ensuring they are reflected in consumer information. However, these comments, questions and criticisms are valid and suggest the need for greater critical debate and input into the guideline process. This should include the role of 'expert consensus' where evidence is less strong, and wider consultation with more practitioners and users before final publication to ensure the best practical uptake and use. In this way we will support improved knowledge and work towards truly harmonised practice for the future.

Statements on funding and competing interests

Funding. None identified.

Competing interests. The author has, in a professional capacity, participated in the development of a number of sexual health guidelines.

Toni Belfield, BSc, FRSH

Director of Information, fpa, 2-12 Pentonville Road, London N1 9FP, UK.E-mail: tonib@fpa.org.uk

References

1 Breen A, Feder G. Where does evidence come from? In: Hutchinson A, Baker R (eds), Making Use of Guidelines in Clinical Practice. Oxford, UK: Radcliffe Medical Press, 1999; Chapter 2, 15-28.
2 Templeton A, Charney M, Thomas J, et al. The implementation and uptake of clinical guidelines in obstetrics and gynaecology. The Obstetrician and Gynaecologist 2003, 3: 93-95.

3 Shaneyfelt TM, Mayo-Smith MF, Rothwangl J. Are guidelines following guidelines? The methodological quality of clinical practice guidelines in the peer-reviewed medical literature. JAMA 1999, 281: 1900-1905.

4 Coomarasamy A, Ola B, Gee $\mathrm{H}$, et al. Quality of brief guidelines produced by professional bodies: a study of the 'green-top' guidelines by the UK Royal College of Obstetricians and Gynaecologists. $J$ Obstet Gynaecol 2003, 23: 479-483.

5 MacGregor A. Evidence-based reproductive medicine (Letter). J Fam Plann Reprod Health Care 2004; 30(1): 64.

6 Mansour D. WHO recommendations (Letter). J Fam Plann Reprod Health Care 2004, 30(2): 131

7 World Health Organization (WHO). Selected Practice Recommendations for Contraceptive Use. Geneva, Switzerland: WHO, 2002.

8 World Health Organization (WHO). Quality of Care in Family Planning. Medical Eligibility Criteria for Contraceptive Use. Geneva, Switzerland: WHO Reproductive Health and Research, 1996.

9 Glasier A, Brechin S, Raine R, et al. A consensus process to adapt the World Health Organization selected practice recommendations for UK use. Contraception 2003, 68: 327-333.

10 Hurwitz B. Legal and political considerations of clinical practice guidelines. BMJ 1999, 318: 661-664.

\title{
OVERVIEW
}

\section{Contraception in Europe: accessibility and availability}

\author{
Medard M Lech, MD, PhD, School of Public Health, National Center of Postgraduate Education, Warsaw, Poland
}

Correspondence: Dr Medard M Lech, School of Public Health, National Center of Postgraduate Education, 2 Lucka Str., Suite 50,00-845 Warsaw,Poland.E-mail: medardlech@poczta.onet.pl

(Accepted 25 April 2004)

\section{Journal of Family Planning and Reproductive Health Care 2004; 30(3): 151-153}

\section{Introduction}

At its special session from 30 June-2 July 1999, the United Nations General Assembly discussed the implementation of the Programme of Action from the Cairo International Conference on Population and Development in 1994. The United Nations General Assembly reaffirmed its commitment to the goal of reproductive health for all and stated that 'Governments should strive to ensure that by 2015 all primary health and family planning facilities are able to provide ... the widest available range of safe and effective family planning and contraceptive methods ...' Five years later, this commitment has yet to be fulfilled, even in European countries. How can we measure progress in the fulfilment of the Programme? Do we have proper indicators for this measurement? And last, but not least, what if health care providers were able to provide safe and effective family planning methods, but the population was not able and not ready (for various reasons) to ask for and use these methods?

It seems pertinent to look at the availability and accessibility of contraception throughout Europe, as this may help to assess the progress in implementation of the Cairo Programme of Action in European countries.

\section{Demographic and social trends among families in \\ Europe}

The total population of Europe in $2003^{1}$ was approximately 726 million; $51.5 \%$ live in Eastern/Central Europe and $48.5 \%$ in Western/Northern Europe. Women represent approximately $52 \%$ of the European population. In some countries (Belarus, Lithuania, Latvia, Poland, Portugal, Russia, Ukraine and Hungary) the number of women exceeds 106 per 100 men, but the excess of women is especially high among the elderly all over Europe. Demographic projections for Europe in 2050 predict a declining population (down to approximately 632 million) and a decreased population growth rate of $-0.1 \%$ per year (projection for the years 2000-2005). During the same period, the total fertility rate (TFR) for Europe is expected to reach 1.38 (in comparison, TFRs for Europe in the years 1990 and 2000 were 1.67 and 1.48 , respectively). The lowest TFRs (approximately 1.10) are expected to be in Bulgaria, Latvia, Slovenia and Spain; the highest TFR values $(>1.80)$ are predicted for Ireland, France, Norway and some Balkan countries. Lowering the TFR depends on changes in lifestyle and understanding of the 'ideal number of children in the family' with its natural consequence; postponement of first birth and reduction in the total number of children (preferably to one or two). The average age at which women in many European countries have their first child is between 28 and 30 years. Conversely, there are very young women (15-19 years of age) who have already given birth. The average European birth rate per 1000 women aged 15-19 years is around 20, but in some countries (e.g. the Balkan and Baltic countries) these rates are approaching 30 and above. Countries that have high birth rates in very young women have a low usage of modern methods of contraception.

\section{Number of children in the family: an essential human right}

It is important that couples have easy access to a wide range of methods of birth control so they can freely exercise their 

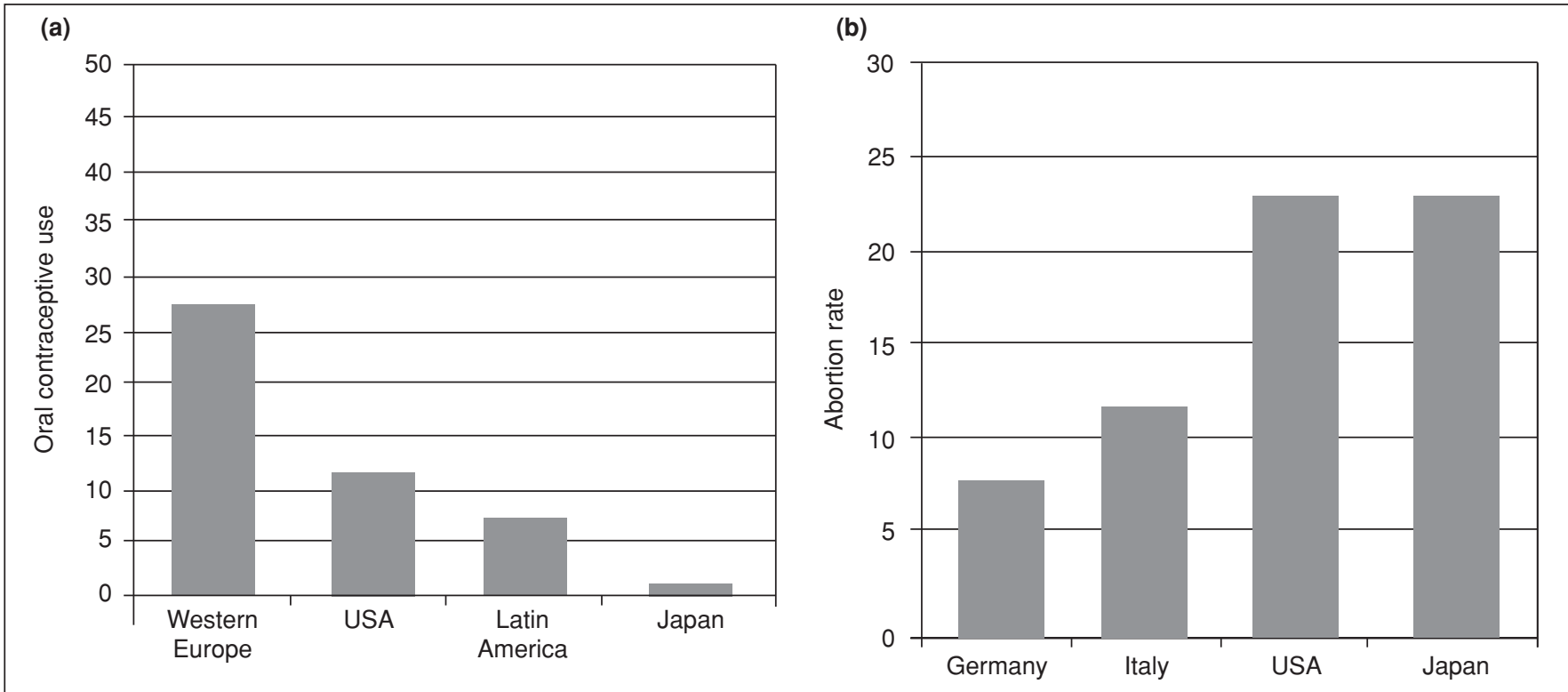

Figure 1 (a) Oral contraceptive use per 1000 women aged 15-44 years. (b) Abortion rates (legal abortions per 1000 women aged 15-44 years) in Germany, Italy, USA and Japan. Source: World Bank adapted from Raff ${ }^{2}$

choice in the matter of procreation. This can be achieved in several ways: sterilisation (male or female), effective contraception or abortion. Abortion should be a 'last resort' method of birth control. Wherever the availability of effective methods of contraception is restricted, the rates of induced abortions are high (Figure 1).

Historically, induced abortion has been a common method of birth control in Central and Eastern Europe due to the lack of modern contraceptives (i.e. any method other than the rhythm method or coitus interruptus). In these countries in 1994, 43\% of women aged 15-44 years used no contraceptive method, $27 \%$ relied on withdrawal and 6\% the rhythm method. In 1996 the contraceptive prevalence rate was still only $35 \% .^{3}$ The increased use of modern contraceptives is directly correlated with declining abortion rates. As an example, the annual number of abortions in the Czech Republic declined by $65 \%$ from 107100 in 1990 to 37200 in 1999 as modern contraceptive use increased seven-fold in the same period of time. ${ }^{4}$ Similarly, increased use of contraception in Finland decreased the number of unintended pregnancies. ${ }^{5}$ In 1975 the number of legal adolescent abortions was at its highest at 21.2 per 1000 women aged 15-19 years. By 1995 the number had decreased to 10 per 1000 . In the same time period the number of adolescent deliveries declined from 27.5 to 10 per 1000 .

A similar inverse correlation can be seen between the abortion rate and use of modern contraception in Romania and Bulgaria in the years 1950-2000 (Figure 2). ${ }^{6}$

Teenage abortion and birth rates in Norway decreased by $34 \%$ and $24 \%$, respectively, in the period 1999-2000 (in comparison with the period 1997-1998) simply by implementing contraceptive counselling and oral contraceptive prescription by public health nurses in youth clinics.

Currently, abortion is legal up to 12 weeks in most European countries, though access is by no means always easy. Ireland, Malta, Poland and Spain have the most restrictive abortion laws; in the case of Ireland, this has resulted in an estimated 5000 women a year travelling to the UK to obtain the procedure. ${ }^{3}$ The estimated number of illegal abortions in Poland was between 90000 and 190000 per year (in 1999). ${ }^{7}$ (a)

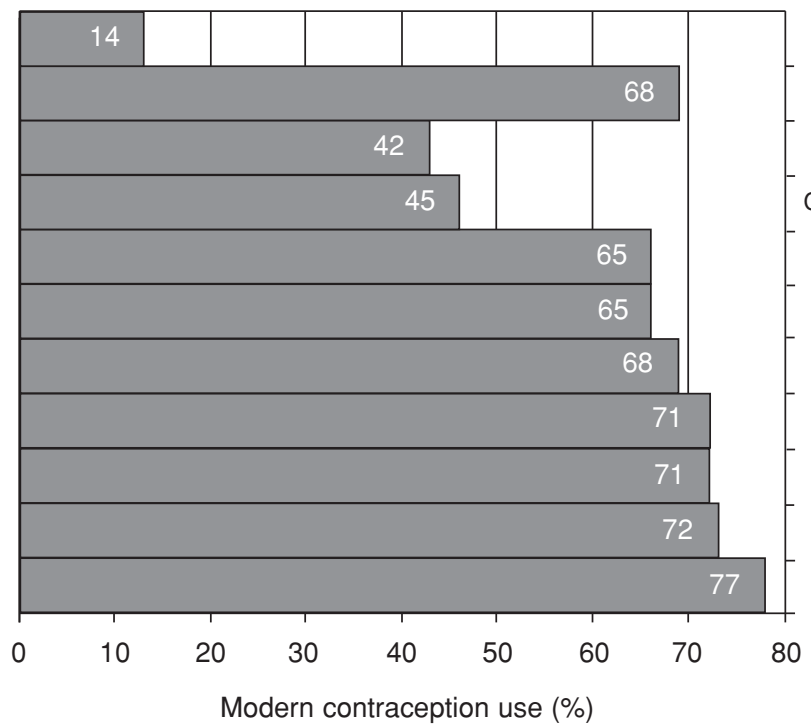

(b)

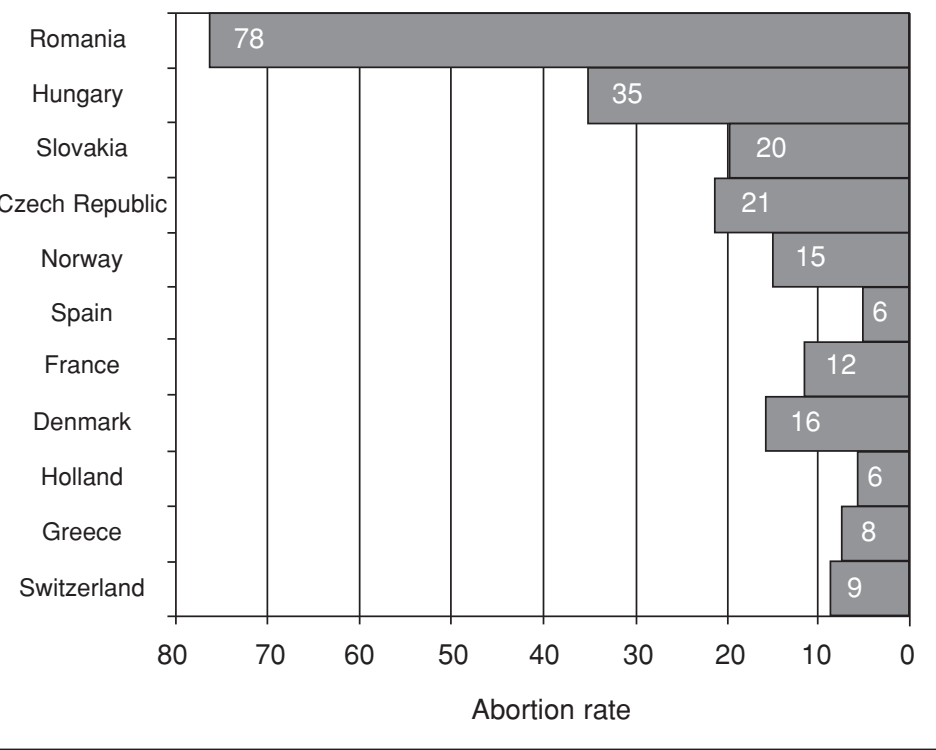

Figure 2 (a) Oral contraceptive use in women aged 15-44 years and (b) abortion rates (legal abortions per 1000 women aged 15-44 years in 1996) in selected European countries. Source: Morston et al. ${ }^{6}$ 


\section{Prevalence of contraception use in Europe}

Prevalence of contraceptive usage in Europe (in women aged 15-49 years) varies from $20-23 \%$ in Lithuania, Moldova and Ukraine to $74-78 \%$ in Denmark, France, Norway and Sweden. ${ }^{3}$ In some countries modern methods of contraception are unpopular (e.g. in Romania the figure for the use of all contraceptive methods is $57 \%$, but for modern methods is only 14\%). In recent years, TFRs all over Europe have fallen, and in most countries have reached less than 1.9 (excluding Albania, Iceland, Cyprus, UK and Turkey). It seems unlikely that this is due to a decrease in sexual activity of people living in Europe; it must therefore be due to increased use of birth control methods, especially the use of modern contraception.

It is very difficult to study the epidemiology of contraception in Europe. The methodology of surveys on contraception and the data from most European countries are not comparable. Surveys have been carried out in different time periods using different methodologies and definitions of study populations. For example in the National Survey on Contraception ${ }^{8}$ the number of people interviewed in Switzerland was 6000 (in the age range 20-49 years) but in Poland they only interviewed women and men between the ages of 15 and 49 years $(n=2743)$ who were in a stable relationship for at least 12 months, while in Spain the survey was carried out only in women $(\mathrm{n}=2218)$.

\section{Availability of modern contraception in Europe}

For an individual to access contraception they need information, availability and accessibility of services and methods. All of these parameters vary considerably within and between countries of Europe. In Western Europe a full range of modern contraceptives is available but in Eastern and Central European countries access to contraceptives is often limited.

\section{Oral contraceptives $(O C)$}

OCs constitute the dominant reversible method of contraception in Europe The number of brands available varies from 10 in Yugoslavia to 81 in Germany. OC failure rates vary from $0.1 \%$ (when used correctly and consistently) to $6-8 \%$ if there is poor compliance. ${ }^{9}$ The French Coraliance Study ${ }^{10}$ showed that $23 \%$ of OC users missed at least one pill during a cycle. More worryingly, $42 \%$ of these missed pills occurred in the first week of the packet, following the pill-free interval. Some $11 \%$ of repeat abortions in Russia occur as a result of OC failure, ${ }^{11}$ most probably as the result of missed pills. In order to improve compliance, many of the OC manufacturers provide electronic reminders for women. These reminders could also be useful for users of other forms of contraception. A particularly innovative idea has been the use of mobile phone text messaging to remind users of the Evra ${ }^{\circledR}$ contraceptive patch of their patch change day.

Accessibility of OCs depends on various factors. In poorer settings the price of contraceptive pills may be a difficult barrier to overcome, especially for adolescents. There is no universal European policy regarding the reimbursement of contraceptive costs. In some countries oral contraceptives are provided free of charge to all (UK) or adolescents (e.g. France), whereas in many other countries (e.g. Poland) it is hard to find even one oral contraceptive on the list for (even partial) reimbursement from the government.

\section{Intrauterine devices (IUDs)}

The copper-bearing IUD is available throughout Europe and is the second most widely used reversible contraceptive. The levonorgestrel-releasing intrauterine system (Mirena ${ }^{\circledR}$ ) is also widely available in Europe and is regarded as a highly effective, long-acting and reversible method of contraception. Some health professionals are reluctant to use these devices in very young (nulliparous) women and there are still strong reservations about IUD use in women at high risk of acquiring sexually transmitted diseases.

\section{Progestogen-only methods}

Depo-Provera ${ }^{\circledR}$, Norplant ${ }^{\circledR}$, Implanon ${ }^{\circledR}$ and progestogenonly pills are available in most Western European countries but in the eastern and central part of the continent access to contraceptive implants is very limited. In Albania, Belarus, Bulgaria, Croatia, Cyprus, Poland and Russia implants containing progestogen are not available at all.

\section{The condom}

The condom is the only reversible male contraceptive available all over the world. New improved condoms made of thinner and yet durable materials are available and widely used in all European countries. The female condom, however, is available only in the countries of Western Europe.

\section{Emergency contraception (EC)}

EC has been defined as the use of a drug or device to prevent pregnancy after intercourse. ${ }^{12}$ EC significantly reduces the risk of an unwanted pregnancy. The contraceptive product (Levonelle ${ }^{\circledR}$ in the UK) containing two tablets of levonorgestrel $(0.75 \mathrm{mg})$ is available in almost all European countries. EC pills have not been registered yet in Croatia, Cyprus and Malta. There are no regulatory barriers to the use of postcoital contraception in Europe, but there are huge differences in their accessibility. In some countries, two tablets of levonorgestrel are available without prescription (France, UK and the Scandinavian countries), while in others the emergency pill is only available on prescription, and even doctors may have reservations about its use. In some countries (Poland and Slovak Republic) there is strong religious opposition to the use of EC, and the media in these countries send out very negative messages, including the idea that EC methods are 'early abortive methods'.

\section{Spermicides}

Nonoxynol-9 (N-9) is the chemical agent most commonly used in spermicides. A wide variety of spermicides containing N-9 is available in all European countries. Unfortunately N-9 appears to have anti-HIV properties only in vitro; recent studies suggest its use may even promote HIV infection. The most recent data ${ }^{13}$ show that in 2003 there were at least 210000 adults and children in Europe and Central Asia newly infected with HIV. There is an urgent need for chemical products for dual protection from HIV and pregnancy. ${ }^{14}$

Table 1 Results of surveys on contraception carried out in some European countries $^{\mathrm{a}}$

\begin{tabular}{lcclr}
\hline \multirow{2}{*}{ Method } & \multicolumn{3}{l}{ Country (year) } \\
\cline { 2 - 5 } & $\begin{array}{l}\text { Spain } \\
(2001)\end{array}$ & $\begin{array}{l}\text { Switzerland } \\
(1997)\end{array}$ & $\begin{array}{l}\text { Slovenia } \\
(1995)\end{array}$ & $\begin{array}{r}\text { Poland } \\
(2002)\end{array}$ \\
\hline Rhythm & 0.6 & 2.3 & 10.0 & 7.0 \\
Coitus interruptus & 2.6 & 2.0 & 16.0 & 13.7 \\
Intauterine device & 4.7 & 5.5 & 14.0 & 2.5 \\
Oral contraception & 19.2 & 36.8 & 32.0 & 16.2 \\
Condom & 29.5 & 16.1 & 14.0 & 22.1 \\
Sterilisation & 11.8 & 18.8 & 1.0 & 0.0 \\
None & 30.9 & 2.1 & 8.0 & 32.6 \\
\hline
\end{tabular}

aAll data in the table are given as percentage values. Source: National Survey on Contraception. 8 


\section{Sterilisation}

Sterilisation rates vary enormously across Europe, though a clear East-West divide can be seen. In general, the East European countries (Czech Republic, Hungary, Latvia, Poland, Russia, Slovakia, Slovenia and Romania) have very low rates, ranging from $0 \%$ to $6 \%$ of contraceptive usage. By contrast, sterilisation rates in Western Europe are generally much higher, with the UK, Belgium and Switzerland ranging between $39 \%$ and $27 \%$, while the other countries have rates mostly between $10 \%$ and $20 \%$ of contraceptive usage. In all countries except the UK, female sterilisation is more common than male sterilisation. However, interestingly, where data are available, it can be seen that female sterilisation rates have been coming down over the last 10 years, while male sterilisation rates are increasing. This may reflect the growing popularity of long-acting, highly effective female contraceptive methods. 15

\section{Conclusions}

Gender equality, family planning, low fertility rates and a good quality of family life are all related to contraceptive use in Europe. For contraceptive use to become part of normal behaviour there needs to be easy access to a wide variety of effective methods. However, not all unwanted pregnancies are the results of contraceptive failure. In many European countries there are still barriers to accessibility to contraception and a lack of proper information and education of young people.

It is to be hoped that the 21 st century will see the introduction of effective, even safer methods of contraception, but, importantly, also that all couples will have access to such methods.

Statements on funding and competing interests Funding. None identified.

Competing interests. None identified.
References

United Nations Population Fund (UNFPA). State of World Population 2003. New York, NY: UNFPA, 2003; 74. http://www.unfpa.org/ publications/index.cfm.

2 Raff WK. Modern trends in health care. Abstract presented at the Gyn Symposium, Warsaw, Poland, March 2002.

3 International Planned Parenthood Federation (IPPF) Country Profiles 2004. http://www.ippf.org.

4 Fait T, Kocourkova J, Uzel R, et al. Changes in abortion and contraception situation in Czech Republic (Abstract). Eur $J$ Contracept Reprod Health Care 2002; 7: 41.

5 Apter D. Adolescent health services: different experiences. In: Bruni V, Dei M (eds), Pediatric and Adolescent Gynecology. Rome, Italy: CIC Edizioni Internationali, 2003; 232-237.

6 Morston C, Cleland J. Relationship between contraception and abortion: a review of the evidence. Int Fam Plan Perspect 2003; 29: 6-13.

7 Polish Federation for Women and Family Planning. The Anti-abortion Law in Poland: Functioning, Social Effects, Attitudes and Behaviors: A Report. September 2000. http://www.federa.org.pl.english/ english1.htm

8 Lech M. Contraceptives in Europe: accessibility and availability. Abstract presented at the 7th Seminar of the European Society of Contraception, Budapest, Hungary, 2003

9 Hatcher RA, Rinechart W, Blackburn R, et al. The Essentials of Contraceptive Technology, a Handbook for Clinic Staff. Baltimore, MD: John Hopkins School of Public Health, Population Information Program, 1997; 4.13-4.18.

10 Aubeny E, Buhler M, Colau JC, et al. Oral contraception: pattern of non-compliance. The Coraliance Study. Eur J Contracept Reprod Health Care 2002; 7: 155-161.

11 Savelieva I. Characteristics and history of women having repeat abortions. Abstract presented at the 7th Seminar of the European Society of Contraception, Budapest, Hungary, 2003.

12 Glasier A. Emergency postcoital contraception. N Engl J Med 1997; 337: $1058-1079$.

13 Joint United Nations Programme on HIV/AIDS/World Health Organization (UNAIDS/WHO). AIDS Epidemic Update, December 2003. http://www.unaids.org/Unaids/EN/Resources/Publications/ corporate+publications/aids+epidemic+update+-+december+ 2003.asp.

14 Lech M. Spermicides 2002: an overview. Eur J Contracept Reprod Health Care 2002; 7: 173-177.

15 Contraceptive Sterilization: Global Issues and Trends. New York, NY: Engender Health, 2002. http://www.engenderhealth.org/res/offc/ steril/factbook/index.html.

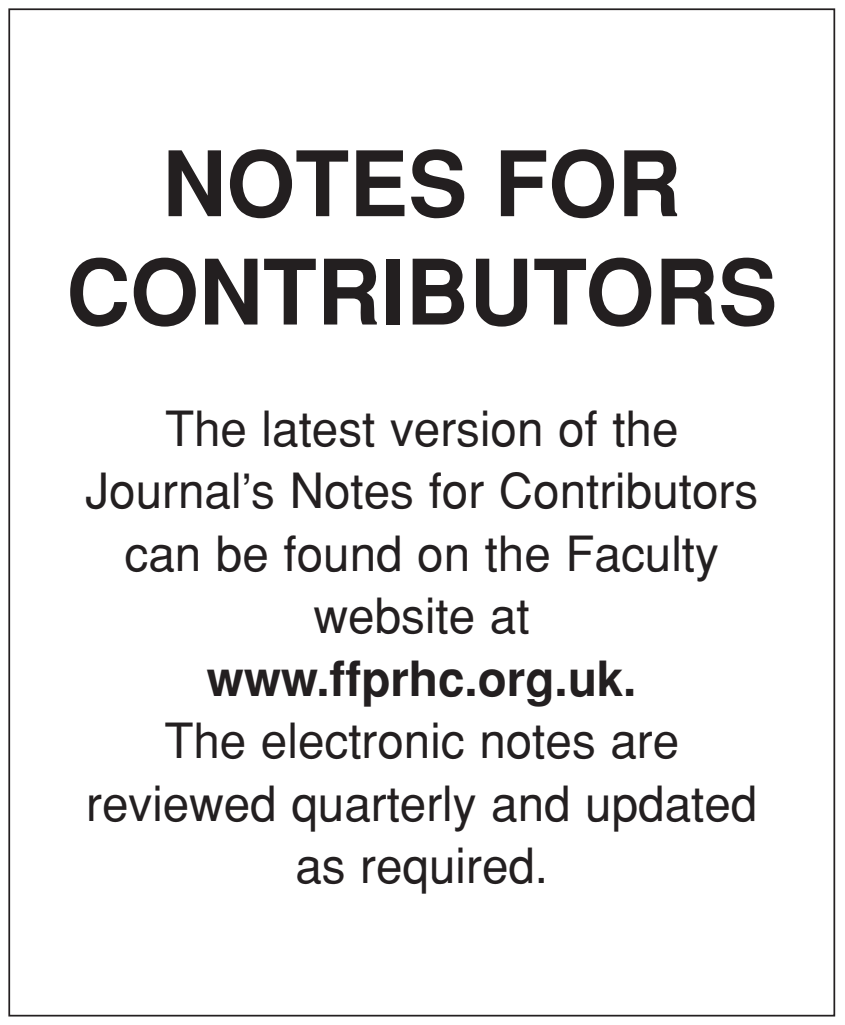

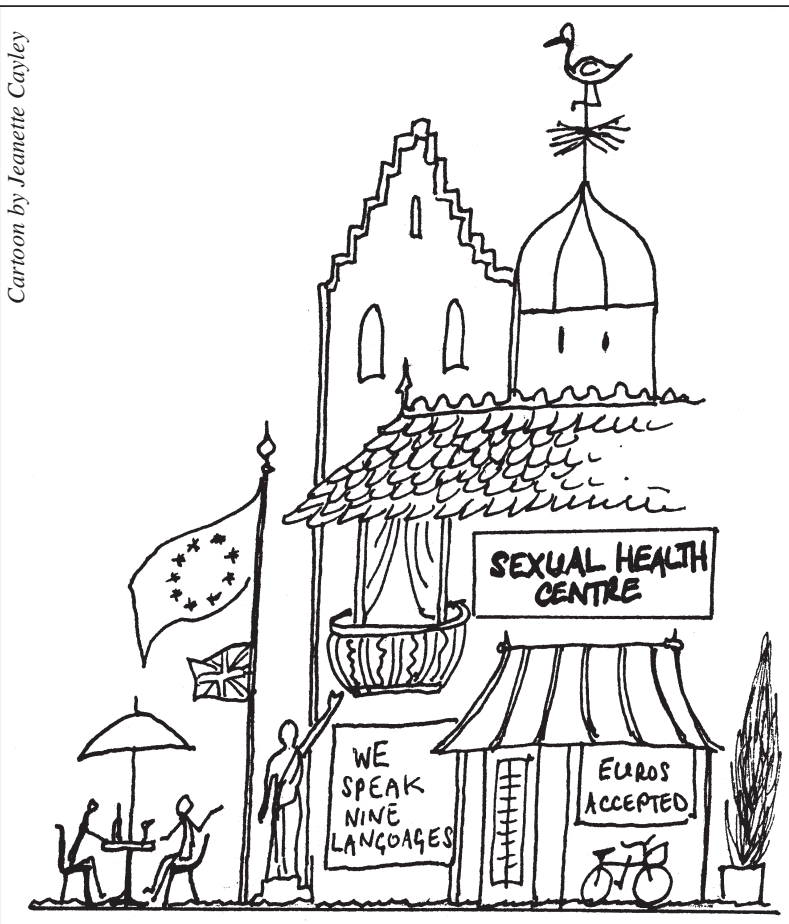

"We're trying to present a more European image." 